\title{
Surface Colonization, Penetration, and Lesion Formation on Grapes Inoculated Fresh or After Cold Storage with Single Airborne Conidia of Botrytis cinerea
}

\author{
Sonja Coertze and Gustav Holz, Department of Plant Pathology, University of Stellenbosch, Private Bag X1, \\ Matieland 7602, South Africa
}

\begin{abstract}
Coertze, S., and Holz, G. 1999. Surface colonization, penetration, and lesion formation on grapes inoculated fresh or after cold storage with single airborne conidia of Botrytis cinerea. Plant Dis. 83:917-924.

Infection of grapes by different densities of airborne conidia of Botrytis cinerea was investigated on table grapes (cultivar Dauphine) harvested ripe $\left(16^{\circ} \mathrm{Brix}\right)$ and inoculated fresh, or after $\mathrm{SO}_{2}$ treatment and 8-week storage at $-0.5^{\circ} \mathrm{C}$. Berries were detached at each inoculation and dusted with dry conidia in a settling tower. Following inoculation, the fresh berries were incubated for $24 \mathrm{~h}$ at high relative humidity $(\geq 93 \%)$, or were overlaid with wet sterile paper towels. Cold-stored berries were incubated at high relative humidity. The effect of conidial density on surface colonization, penetration, and lesion formation was determined by surface sterilization, isolation, and freezing studies on fresh berries. Only symptom expression was determined on cold-stored berries. Fluorescence microscopy of skin segments showed that conidia were consistently deposited as single cells, and not in pairs or groups, on berry surfaces. Individual conidia, at all densities tested, readily infected the cold-stored berries and formed separate lesions after 2 days. Although the cold-stored berries were highly susceptible, lesion numbers were not related to conidial density at low inoculum dosages ( 0.67 to 2.60 conidia per $\mathrm{mm}^{2}$ berry surface). Lesion numbers tended to increase exponentially at higher dosages ( 3.24 to 3.88 conidia per $\mathrm{mm}^{2}$ berry surface). Individual conidia, however, did not induce any disease symptoms on fresh berries. Removal of the pathogen after 24-h incubation from the surface of fresh berries by ethanol, and subsequent incubation of excised skin segments revealed that, irrespective of the conidial density or the wetness regime, less than $2 \%$ of skin segments were penetrated. Furthermore, increasing densities of conidia did not lead to higher rates of surface colonization and skin penetration. The low incidence of disease caused on fresh berries and high disease incidence induced after prolonged cold storage indicated that infection was not governed by conidial density on berry surfaces, but by the level of host resistance.
\end{abstract}

Additional keywords: host response, inoculum dose

Botrytis cinerea, a pathogen of grapevine (Vitis vinifera), can attack most of the plant's organs. The pathogen exists in grapevines as sclerotia (39), conidia (4,7), and mycelia $(17,44)$. Conidia-bearing sclerotia on grapevines are a source of primary inoculum for infection of berries, on which the most prominent symptom of the disease is found (39). Conidia are dispersed in air currents (23), in splashing water droplets $(24)$, and by insects $(14,15,28)$. Floral debris bearing mycelia are dispersed in wind and rain (25). Although the different inocula may be present throughout the growing season (38), grape berries are considered to be relatively resistant to infection during the early developmental stages and become relatively susceptible after véraison (19). In spite of this differ-

Corresponding author: Gustav Holz

E-mail: gh@land.sun.ac.za

Accepted for publication 14 June 1999.

Publication no. D-1999-0802-01R

(C) 1999 The American Phytopathological Society ential susceptibility, conidial infection of flowers and berries may destroy immature fruit $(31,40)$. Incipient flower infections cause late-season bunch rot following a period of fungal latency in the style end of the berry $(31,40)$, or in the receptacle part of the pedicel $(20,21,46)$. In addition to, or contrasting with, fungal latency, colonized senescent floral tissues and aborted berries can serve as conidial and mycelial inocu$\operatorname{lum}(17,18,44,46)$ for late-season infections of sound berries.

Disease prediction models $(2,3,32,34,55)$ have been developed to provide fungicide spray recommendations for $B$. cinerea bunch rot control. These models rely on infield environmental monitoring stations that predict when conditions are conducive to sporulation or infection. Different pathogen- and host-related parameters are included to enhance the effectiveness of these models. Bulit's model (3) included pathogen inoculum density. Strizyk (55) included effects of host susceptibility due to phenology and cultivar, as well as temperature and humidity effects on infection, germination, and sporulation. Nair et al. (37) suggested that $B$. cinerea bunch rot can be inoculum-driven and demonstrated that quantitative relationships exist between inoculum levels at carryover, flowering, and harvest stages of the season.

For a facultative saprophyte such as $B$. cinerea, inoculum in vineyards is almost always present and may not be as important a parameter as presence or absence of a conducive environment (2). However, little is known about the relationship between conidial density of $B$. cinerea on grape berry surfaces and disease development. Corbaz (7) and Bulit and Verdu (4) found a fluctuation in the concentration of $B$. cinerea conidia in the air during the growing season in French vineyards; the highest numbers occurred from véraison to vintage. On the other hand, data on washings made from grape berries in Californian (11) and South African vineyards (G. Holz, unpublished data) indicated that the amount of $B$. cinerea on berry surfaces was very low throughout the season, and $B$. cinerea occurred as single CFU. Very few of the $B$. cinerea conidia dispersed by rain drops become wet enough to enter the droplets, and the majority are carried on the droplet surface as a dry coating (24). Conidia of $B$. cinerea attach in two distinct stages to hydrophobic surfaces $(9,10)$. The first stage, immediate adhesion, occurs upon hydration of freshly deposited conidia. Conidia of $B$. cinerea adhere more strongly when applied in water suspension or to the wet surface of grape berries than when dry conidia were applied to a dry surface (54). Raindrops may therefore deposit conidia carried on their surfaces as single cells onto berry surfaces during runoff. These findings imply that infections by single conidia should play a prominent role in the epidemiology of this disease. However, Hill et al. (19) calculated that from a total of about 3,500 conidia per $15.9 \mathrm{~mm}^{2}$ cuticle surface, only one to two conidia were able to penetrate the isolated cuticle layer, which points to the necessity for high inoculum levels on berry surfaces for successful infection.

Groups of conidia are deposited as a standard procedure in most studies where grape berries are artificially inoculated $(1,2,5,30,33,41)$. Dry conidia were successful in causing disease when grape clusters were dusted en masse and kept humid $(31,41)$. The objective of this work was to study surface colonization, penetration, and lesion formation by different numbers of single airborne conidia of $B$. 
cinerea dispersed dry in an inoculation tower at several sites on grape berry surfaces. Ripe table grapes, freshly harvested or subjected to $\mathrm{SO}_{2}$ treatment and prolonged cold storage, were used for the study. Grape berries are normally considered relatively susceptible $(2,19,34,41)$ to decay by groups of conidia of $B$. cinerea when ripe, but highly susceptible $(41,42)$ when subjected to $\mathrm{SO}_{2}$ treatment and prolonged cold storage.

\section{MATERIALS AND METHODS}

Grapes. Grape bunches (cultivar Dauphine) were selected at vintage $\left(16^{\circ} \mathrm{Brix}\right)$ from a vineyard with a history of low incidence of $B$. cinerea. Following harvest, the bunches were sterilized $(30 \mathrm{~s}$ in $70 \%$ ethanol, 2 min in $0.35 \%$ sodium hypochlorite, $30 \mathrm{~s}$ in $70 \%$ ethanol) and air-dried. This treatment completely eliminated $B$. cinerea from the berry surface (49) and prevented natural infection. At each inoculation, berries were cut from clusters with short stem segments attached and packed on sterile epoxy-coated steel mesh screens $(53 \times 28$ $\times 2 \mathrm{~cm}$ ). In order to recognize the inoculated side of the berry at a later stage, a 1$\mathrm{cm}$ mark was made on the berry near the pedicel with a soft-tipped felt pen (preliminary studies showed no phytotoxic effect on berries).

Inoculum. A virulent isolate of $B$. cinerea, obtained from a naturally infected grape berry, was maintained on potato dextrose agar (PDA) at $5^{\circ} \mathrm{C}$. For the preparation of inoculum, the isolate was first grown on canned apricot halves. Conidiophores from the colonized fruit were transferred to PDA in petri dishes and incubated at $22^{\circ} \mathrm{C}$ under a diurnal light regime $(12 \mathrm{~h}$ near-ultraviolet light). Conidia were harvested dry with a suction-type collector from 14-day-old cultures and stored dry at $5^{\circ} \mathrm{C}$ until use ( 1 to 16 weeks). Storage time did not affect germination; the dry conidia could therefore be used in all experiments (54).

Conidial dispersal. For inoculation, dry conidia were dispersed by air pressure into the top of an inoculation tower according to the method of Salinas et al. (48) and allowed $20 \mathrm{~min}$ to settle onto the berries, which were positioned on two screens. The dimensions of the Plexiglas tower were $3 \times$ $1 \times 1 \mathrm{~m}$ (height $\times$ depth $\times$ width). Inoculation was done at $22^{\circ} \mathrm{C}$ and $40 \%$ relative humidity. To determine the distribution of conidia on the floor of the tower and the consistency of inoculation, the following experiment was conducted. Ten petroleumjelly-coated microscope slides were placed equidistant on the screens (five slides per screen), and the screens were put on the floor of the tower. Three milligrams of dry conidia were dispersed into the tower. After $20 \mathrm{~min}$, the slides were replaced and the process was repeated. Eleven successive inoculations were done, and the number of conidia in 10 microscope fields $(\times 20)$ on each slide was counted. For each slide, the average number of conidia per microscope field was calculated. The data were analyzed using a two-way analysis of variance to test for differences between positions, of which there were 10, and inoculations, of which there were 11.

Conidial density on grape berries. Groups of berries (two screens of 24 berries per dose) were dusted with $0.5,1.0$, $1.5,2.0,2.5$, and $3.0 \mathrm{mg}$ of conidia. After inoculation, berries were incubated at $22^{\circ} \mathrm{C}$ for $6 \mathrm{~h}$ in perspex (Cape Plastics, Cape Town, South Africa) chambers $(60 \times 30 \times$ $60 \mathrm{~cm})$. The chambers were lined with a sheet of chromatography paper with the base resting in deionized water to establish high relative humidity $(\geq 93 \% \quad \mathrm{RH})$. Incubation under these conditions facilitates conidial adhesion to the fruit surface (54). Actual conidial density on the berry surface was determined by counting the number of conidia on skin segments (five berries per inoculum dose, three segments per berry). Thin hand-sectioned pieces $(7 \times$ $5 \mathrm{~mm}$ ) of skin comprising the cuticle, epidermis, and a few layers of cells were cut with a razor blade. The sections were stained for $5 \mathrm{~min}$ in a differential stain containing fluorescein diacetate (FDA; Sigma Chemical Co., St. Louis, MO), aniline blue (AB; B.D.H. Laboratory Chemicals Division, Poole, England), and blankophor (BP; Bayer, Germany), mounted on a glass slide in $0.1 \mathrm{M} \mathrm{KH}_{2} \mathrm{PO}_{4}$ buffer $(\mathrm{pH}$ 5.0), and covered with a coverslip. FDA (2 $\mathrm{mg}$ per $\mathrm{ml}$ acetone) and $\mathrm{AB}(0.1 \%$ in $\mathrm{KH}_{2} \mathrm{PO}_{4}$ buffer, $\mathrm{pH}$ 5.0) were prepared as stock solutions and stored at $-20^{\circ} \mathrm{C}$ and $5^{\circ} \mathrm{C}$, respectively. Before a histology session, $\mathrm{BP}(0.5 \%)$ was added to the AB solution, and a fresh stain was prepared by mixing $25 \mu \mathrm{l}$ of the FDA stock solution with $1 \mathrm{ml}$ of the $\mathrm{AB} / \mathrm{BP}$ stock solution in a 1.5-ml polypropylene Eppendorf tube, which was then kept on ice. Conidial counts on stained sections were made with the aid of a Zeiss Axioskop microscope equipped with an epifluorescence condenser, a high-pressure mercury lamp, Neofluar objectives, and Zeiss filters 02, 06 , and 18. These sets include excitation filters G 365, BP 436/8, and BP 395-425, respectively. With this setup, protoplasts of viable fungal structures fluoresced brilliantly yellow-green with filters 02,06 , and 18. Protoplasts of dead cells were blueblack (filters 06 and 18), whereas cells without protoplasts fluoresced white (filter 02) or yellow (filter 18) (45). The experiment was performed twice.

Effect of conidial density on infection. Berries from freshly harvested bunches were used for determining the effect of conidial density on the different stages of infection, namely surface colonization, penetration, and lesion formation. Twelve ethanol-disinfected perspex chambers with high relative humidity were prepared as described previously. Each chamber con- tained six screens, and 94 berries were placed on each screen. Each screen in a chamber was randomly assigned one of six doses. These were $0.5,1.0,1.5,2.0,2.5$, and $3.0 \mathrm{mg}$ of conidia. Each chamber was considered a block, and the screens were randomized within each chamber. Berries in six chambers were overlaid with sterile paper towels wetted with sterile deionized water, whereas the berries in the other chambers were left dry. These conditions provided two different wetness regimes for the pathogen: dry conidia on dry berries under high relative humidity, and conidia exposed to a film of water on the berry surface. The chambers were incubated at $22^{\circ} \mathrm{C}$ with a 12 -h photoperiod daily. After $24 \mathrm{~h}$, the screens and the paper towels were removed from the moist chambers. Screens from six of the chambers (three chambers per wetness regime) were transferred to identical dry perspex chambers $(\leq 56 \%$ $\mathrm{RH}$ ), and the berries were examined daily for disease development. The number of berries with decay was recorded after 14 days. Berries from the remaining six chambers were used for determining surface colonization and cuticle penetration. For these studies, berries on the screens in each chamber were divided into two groups of 47 berries. One group on each screen was sterilized in $70 \%$ ethanol for $5 \mathrm{~s}$ to eliminate the pathogen on the berry surface (50), and the other group was left untreated. Seven berries from each group on each screen were then used for isolation, and the remaining 40 berries were frozen.

In the isolation studies, six adjoining epidermal tissue segments $(5 \times 7 \mathrm{~mm})$ were cut from the inoculated cheek of each berry, placed with the cuticle upward on $B$. cinerea selective medium (26), and incubated for 14 days at $22^{\circ} \mathrm{C}$. The segments were examined daily for fungal growth, loss in turgidity, and cell discoloration using a dissecting microscope. In the freezing studies, berries were kept for $1 \mathrm{~h}$ at $-12^{\circ} \mathrm{C}$ and incubated in a dry chamber for 14 days at $22^{\circ} \mathrm{C}$.

Previous studies (22) conducted with naturally infected and artificially inoculated berries showed that a 1-h freezing period at $-12^{\circ} \mathrm{C}$ is needed to promote the development of established infections. The frozen berries were examined daily for fissures or cracks in the cuticle using a dissecting microscope. The numbers of segments and frozen berries yielding $B$. cinerea were recorded after 14 days. The experiment was repeated. In the first run (experiment 1), berries were inoculated on the day following harvest, and in the repeat (experiment 2), berries were inoculated after 1 week of storage at $5^{\circ} \mathrm{C}$.

Cold-stored grapes were used for determining symptom expression (experiment 3 ). Berries were detached from bunches that were packed with an $\mathrm{SO}_{2}$ generator ( 0.3 to $0.55 \mathrm{~g}$ of $\mathrm{Na}_{2} \mathrm{~S}_{2} \mathrm{O}_{5}$ affixed to a paper 
sheet $[27,43])$ inside a polyethylene bag in corrugated boxes (Patent no. RSA 75/6116) and were kept in cold storage for 8 weeks at $-0.5^{\circ} \mathrm{C}$. The berries were dusted with conidia at different inoculum dosages as described before. These berries were incubated at high relative humidity. After 3 days, when lesions were clearly noticeable, the berries were removed and the number of lesions that developed on each berry was counted. Berries without lesions were frozen and kept as described previously. The number of frozen berries yielding $B$.

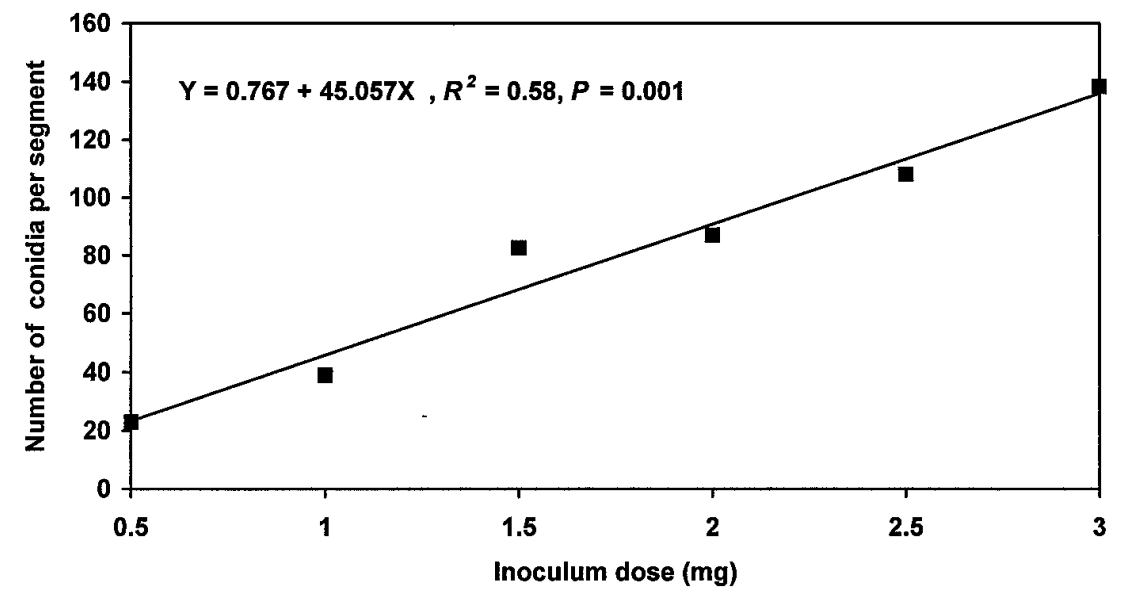

Fig. 1. Mean number of conidia counted using fluorescence microscopy on skin segments $(5 \times 7$ $\mathrm{mm}$ ) obtained from berries inoculated with different dosages of single airborne conidia of Botrytis cinerea and incubated for $6 \mathrm{~h}$ at high relative humidity ( $\geq 93 \%)$. Points represent actual means of two experiments. cinerea was recorded after 14 days. The percentage of berries infected (berries showing lesions after 3 days and frozen, sporulating berries) at each inoculum dose was then calculated. The experiment was repeated.

Statistical analysis. Statistical computations were performed using SAS (SAS Institute, Cary, NC). Observations of repeated experiments were subjected to Bartlett's test for homogeneity of variance, and the data were weighted when appropriate with the reciprocals of the error vari- ances. Data were also tested for normality, and if necessary, a suitable transformation $[y=\ln (x+1)]$ was performed. Data of experiments 1 and 2 were analyzed as a split-plot design, with sterilization regimes as the subplots. Therefore, the main effects within each of the two sterilization regimes were experiment, dose, and wetness regime. The blocks were used as replicates. Pairs of treatment means were compared using Student's $t$-LSD $(P \leq 0.05)$ (53). Regression analyses were used to determine relationships in incidence of infection between inoculum concentration and wetness regime. A separate regression line was fitted to each treatment combination, and intercepts and slopes were compared using Student's $t$-LSD $(P \leq 0.05)$. Intercepts and slopes that did not differ significantly $(P \leq$ 0.05 ) were pooled, and a common regression coefficient was determined.

\section{RESULTS}

Conidial dispersal on glass slides. Conidia were consistently deposited as single cells, and not in pairs or groups, on the glass slides placed at different positions on screens on the floor of the settling tower. Numbers of conidia on slides did not differ significantly $(P=0.1505)$, which showed that the airborne conidia were evenly distributed on the floor of the settling tower, with an average of $1.68 \pm 0.05$ per microscopic field. The average number of conidia recorded per microscopic field for 11 successive inoculations ranged from

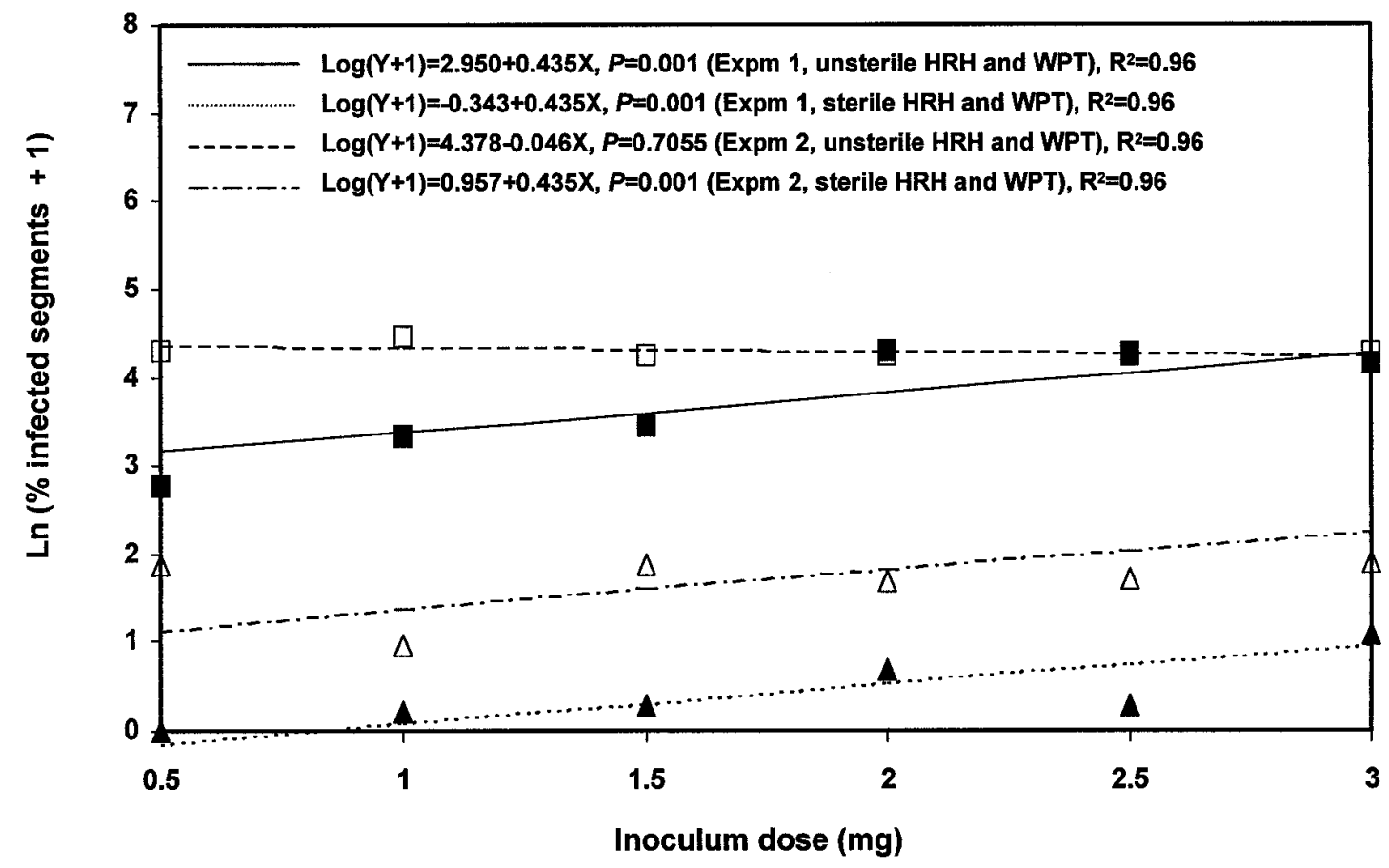

Fig. 2. Effect of wetness and sterility regime on the infectivity of single airborne conidia of Botrytis cinerea dispersed at different dosages on fresh Dauphine grape berries. Incidence of $B$. cinerea is represented by the log-transformed values of the percentage of excised skin segments yielding the pathogen after 14 days of incubation on $B$. cinerea selective medium. Berries used in experiment 1 were inoculated on the day following harvest, whereas those in experiment 2 were inoculated after 1 week of storage at $5^{\circ} \mathrm{C}$. Data for berries incubated under two wetness regimes (high relative humidity [HRH] or overlaid with wet paper towels [WPT]) did not differ significantly in all treatments and are therefore represented by the same line. Points represent actual means. $R^{2}$ for full regression model was 0.96 . 
0.8 to 2.7 . The analysis of variance indicated that deposition between successive inoculations differed significantly $(P=$ 0.001).

Conidial dispersal at different inoculum dosages on grape berries. The airborne inoculum consisted of conidia only, based on fluorescence microscopy of the stained segments. No hyphal fragments were observed. Conidia were consistently deposited as single cells, and not in pairs or groups, on berry surfaces. There was a linear increase $(P \leq 0.05)$ in the number of conidia with an increase in inoculum dose (Fig. 1).

Effect of conidial density on infection. Microscopic observations of skin segments from fresh berries, excised $24 \mathrm{~h}$ after inoculation and incubated on the selective medium, revealed that $B$. cinerea followed a similar growth pattern on segments from unsterilized and surface-sterilized berries. In both instances, no superficial mycelial growth was observed on the segments during the early phases of pathogen development. Hyphae invariably grew from cells underlying the cuticle into the medium. This hyphal outgrowth was observed after 3 days on segments from unsterile berries, and after 5 days on segments from surface-sterilized berries. Excised skin segments that were uninfected retained their turgidity and remained green for 6 days, after which color changes indicative of natural cell death appeared. There were higher order interactions $(P=0.002)$ among wetness regime, inoculum dose, and sterility regime. The incidence of $B$. cinerea plotted on inoculum dose had a common positive slope in the sterile and unsterile regimes in experiment 1 and in the sterile regime in experiment 2 , regardless of the wetness regime (Fig. 2). However, in the unsterile regime in experiment 2 , the regression was not significant and the incidence of infection was consistently high at all inoculum doses. These differences in slopes were probably the cause of the higher order interactions and the interactions between wetness and sterility regimes $(P<0.001)$ (Table 1$)$. Segments removed from berries inoculated on the

Table 1. Analysis of variance for effects of wetness regime (W), inoculum dose (D), sterility regime (S), and interactions on the incidence of Botrytis cinerea on skin segments of Dauphine grape berries inoculated after harvest with single airborne conidia

\begin{tabular}{lrcrc}
\hline Source & df & Sum of squares & $\boldsymbol{F}$ & $\boldsymbol{P}$ \\
\hline Experiment (E) & 1 & 31.9933 & 80.39 & 0.0001 \\
Dose (D) & 5 & 12.1715 & 6.12 & 0.0002 \\
Wetness (W) & 1 & 0.3216 & 0.81 & 0.3732 \\
$\mathrm{~W} \times \mathrm{D}$ & 5 & 0.9479 & 0.48 & 0.7921 \\
$\mathrm{E} \times \mathrm{D}$ & 5 & 3.8628 & 1.94 & 0.1048 \\
$\mathrm{E} \times \mathrm{W}$ & 1 & 1.1183 & 2.81 & 0.1002 \\
$\mathrm{E} \times \mathrm{W} \times \mathrm{D}$ & 5 & 1.1431 & 0.57 & 0.7192 \\
Error $(\mathrm{a})$ & 48 & 19.104 & & \\
Sterility $(\mathrm{S})$ & 1 & 310.2998 & 885.39 & 0.0001 \\
$\mathrm{D} \times \mathrm{S}$ & 5 & 1.3439 & 0.77 & 0.5782 \\
$\mathrm{~W} \times \mathrm{S}$ & 1 & 4.5217 & 12.90 & 0.0008 \\
$\mathrm{~W} \times \mathrm{D} \times \mathrm{S}$ & 5 & 1.5654 & 0.89 & 0.4931 \\
$\mathrm{E} \times \mathrm{D} \times \mathrm{S}$ & 6 & 8.8516 & 4.21 & 0.0018 \\
$\mathrm{E} \times \mathrm{W} \times \mathrm{S}$ & 1 & 0.0011 & 0.00 & 0.9553 \\
$\mathrm{E} \times \mathrm{W} \times \mathrm{D} \times \mathrm{S}$ & 5 & 1.8083 & 1.03 & 0.4097 \\
Error $(\mathrm{b})$ & 48 & 16.8224 & & \\
Corrected total & 143 & 415.8769 & & \\
\hline
\end{tabular}

Table 2. Analysis of variance for effects of wetness regime (W), inoculum dose (D), sterility regime (S), and interactions on the incidence of Botrytis cinerea on frozen Dauphine grape berries inoculated after harvest with single airborne conidia

\begin{tabular}{lrcrc}
\hline Source & df & Sum of squares & $\boldsymbol{F}$ & $\boldsymbol{P}$ \\
\hline Experiment (E) & 1 & 73.4412 & 97.59 & 0.0001 \\
Dose (D) & 5 & 9.0799 & 2.41 & 0.0496 \\
Wetness (W) & 1 & 1.2795 & 1.70 & 0.1985 \\
$\mathrm{~W} \times \mathrm{D}$ & 5 & 3.5372 & 0.94 & 0.4638 \\
$\mathrm{E} \times \mathrm{D}$ & 5 & 3.9279 & 1.04 & 0.4030 \\
$\mathrm{E} \times \mathrm{W}$ & 1 & 1.6781 & 2.23 & 0.1419 \\
$\mathrm{E} \times \mathrm{W} \times \mathrm{D}$ & 5 & 7.2686 & 1.93 & 0.1064 \\
Error (a) & 48 & 36.1217 & & \\
Sterility $(\mathrm{S})$ & 1 & 0.5326 & 0.74 & 0.3952 \\
$\mathrm{D} \times \mathrm{S}$ & 5 & 5.8053 & 1.60 & 0.1770 \\
$\mathrm{~W} \times \mathrm{S}$ & 1 & 0.9994 & 1.38 & 0.2457 \\
$\mathrm{~W} \times \mathrm{D} \times \mathrm{S}$ & 5 & 3.0078 & 0.83 & 0.5339 \\
$\mathrm{E} \times \mathrm{D} \times \mathrm{S}$ & 6 & 3.1637 & 0.73 & 0.6288 \\
$\mathrm{E} \times \mathrm{W} \times \mathrm{S}$ & 1 & 0.4187 & 0.58 & 0.4506 \\
$\mathrm{E} \times \mathrm{W} \times \mathrm{D} \times \mathrm{S}$ & 5 & 0.7796 & 0.22 & 0.9543 \\
Error $(\mathrm{b})$ & 48 & 34.7360 & & \\
Corrected total & 143 & 185.7770 & & \\
\hline
\end{tabular}

day following harvest (experiment 1) had lower levels of infection than segments removed from berries inoculated after 1 week of storage at $5^{\circ} \mathrm{C}$ (experiment 2). This is indicated by the lower intercepts at the regression of interaction on dose for unsterilized berries in experiment 1 versus unsterile berries in experiment 2 , and for sterilized berries in experiment 1 versus sterilized berries in experiment 2 . In both experiments, the number of segments yielding $B$. cinerea was significantly reduced by surface sterilization (see intercept values, Fig. 2).

Microscope observations showed that the 1-h freezing period had no effect on the integrity of the cuticle. Furthermore, pathogen development followed a similar pattern on berries of both sterility regimes. Decay developed, irrespective of the inoculum dosage, predominantly from one discolored area on the berry surface. There were no interactions among wetness regime, dose, and sterility regime, indicating that infection levels increased at the same rate regardless of wetness or sterility regimes (Table 2). In the freezing studies (Fig. 3), there were significant differences between experiments 1 and $2(P<0.001)$. Berries inoculated on the day following harvest (experiment 1) had lower levels of infection (lower intercepts, Fig. 3) than berries inoculated after 1 week of storage at $5^{\circ} \mathrm{C}$ (experiment 2). In both experiments, surface sterilization had no effect $(P$ $=0.395)$ on the incidence of frozen berries yielding the pathogen. There was no interaction between sterility regime and inoculum dose $(P=0.177)$, indicating that an increase in inoculum dose resulted in the same rate of increase in incidence of $B$. cinerea, irrespective of the sterility regime. In experiments 1 and 2 , in the case of unsterile moist berries, there was a higher rate of increase in the incidence of the pathogen than in the case of sterile moist berries, as well as wet berries under both sterility regimes. This is reflected by the steeper slope of the regression of incidence of $B$. cinerea on inoculum dose. There was no interaction $(P=0.464)$ between dose and wetness regime. The slopes of the lines were significant but not large in all cases, indicating that a large increase in inoculum dose resulted in a small increase in log of incidence of infection. However, the inocula did not form lesions on both groups (experiments 1 and 2) of berries during the 14-day incubation period in dry perspex chambers. This finding further indicated that no natural $B$. cinerea infection occurred on berries used in the experiment.

On the berries inoculated after $\mathrm{SO}_{2}$ treatment and 8 weeks of storage at $-0.5^{\circ} \mathrm{C}$ (experiment 3 ), lesions were visible after 2 days as brown freckles approximately the same size as lenticels. They were dispersed on the upper half of the berry surface and were most noticeable 3 days after inoculation (Fig. 4). Some of the lesions were 
close to each other. To distinguish them as separate lesions, they were counted under a stereo microscope. Based on the number of berries showing lesions after 3 days, the rate of increase in the number of lesions increased exponentially with dose (Fig. 5). There was a linear increase in the percent infected berries on inoculum dose $(25.53 \%$ with every $1-\mathrm{mg}$ increase in dose $)(P \leq$ 0.05 ) (Fig. 6). However, the total percentage of berries infected (berries showing lesions after 3 days and frozen, sporulating berries after 14 days of incubation) was curvilinearly related to inoculum dosage. The rate of the curve increased rapidly at low dosages but leveled off at higher dosages.

\section{DISCUSSION}

This study showed that inoculation with dry airborne conidia of $B$. cinerea in a settling tower is controllable, and that conidia are evenly deposited as single cells on grape berry surfaces. The single conidia, at all densities tested, readily infected the cold-stored berries under high humidity and formed separate lesions after 2 days. The induction of separate lesions on coldstored berries confirmed the potential infectivity of single airborne conidia of the pathogen on grapevine. Although berries are considered highly susceptible $(41,42)$ after prolonged cold storage, lesion numbers were not related to conidial density at low inoculum dosages ( 0.67 to 2.60 conidia per $\mathrm{mm}^{2}$ of berry surface). Lesion numbers tended to increase exponentially at higher dosages (3.24 to 3.88 conidia per $\mathrm{mm}^{2}$ of berry surface). Single airborne conidia, however, did not induce any disease symptoms on fresh berries, which are considered relatively susceptible $(2,19,34,41)$ in the ripe stage.

Removal of the pathogen from the surface of fresh berries by ethanol after $24 \mathrm{~h}$ of incubation and subsequent incubation of excised skin segments revealed that, irrespective of the conidial density or the wetness regime, less than $2 \%$ of skin segments

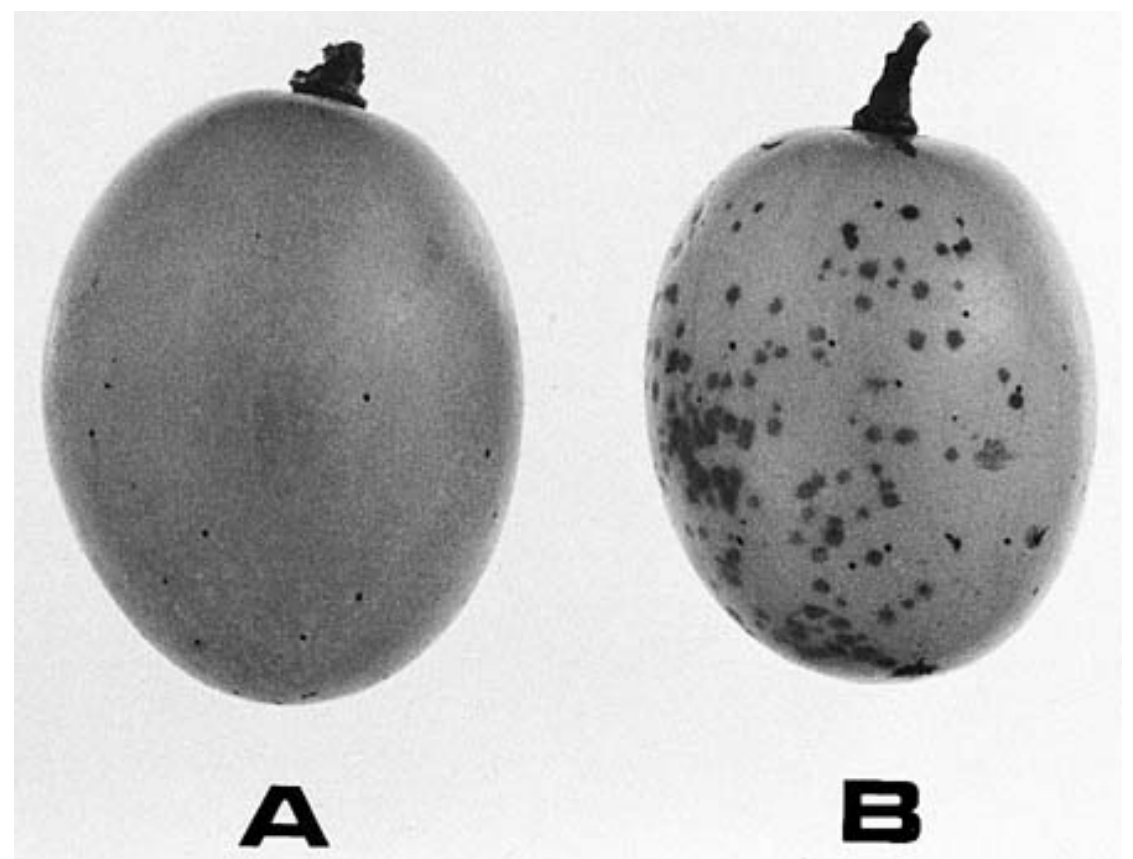

Fig. 4. Lesion formation on ripe Dauphine grape berries 3 days after inoculation with $3 \mathrm{mg}$ of dry conidia of Botrytis cinerea. (A) Berries inoculated on the day following harvest. (B) Berries inoculated after $\mathrm{SO}_{2}$ treatment and 8 weeks of storage at $-0.5^{\circ} \mathrm{C}$.

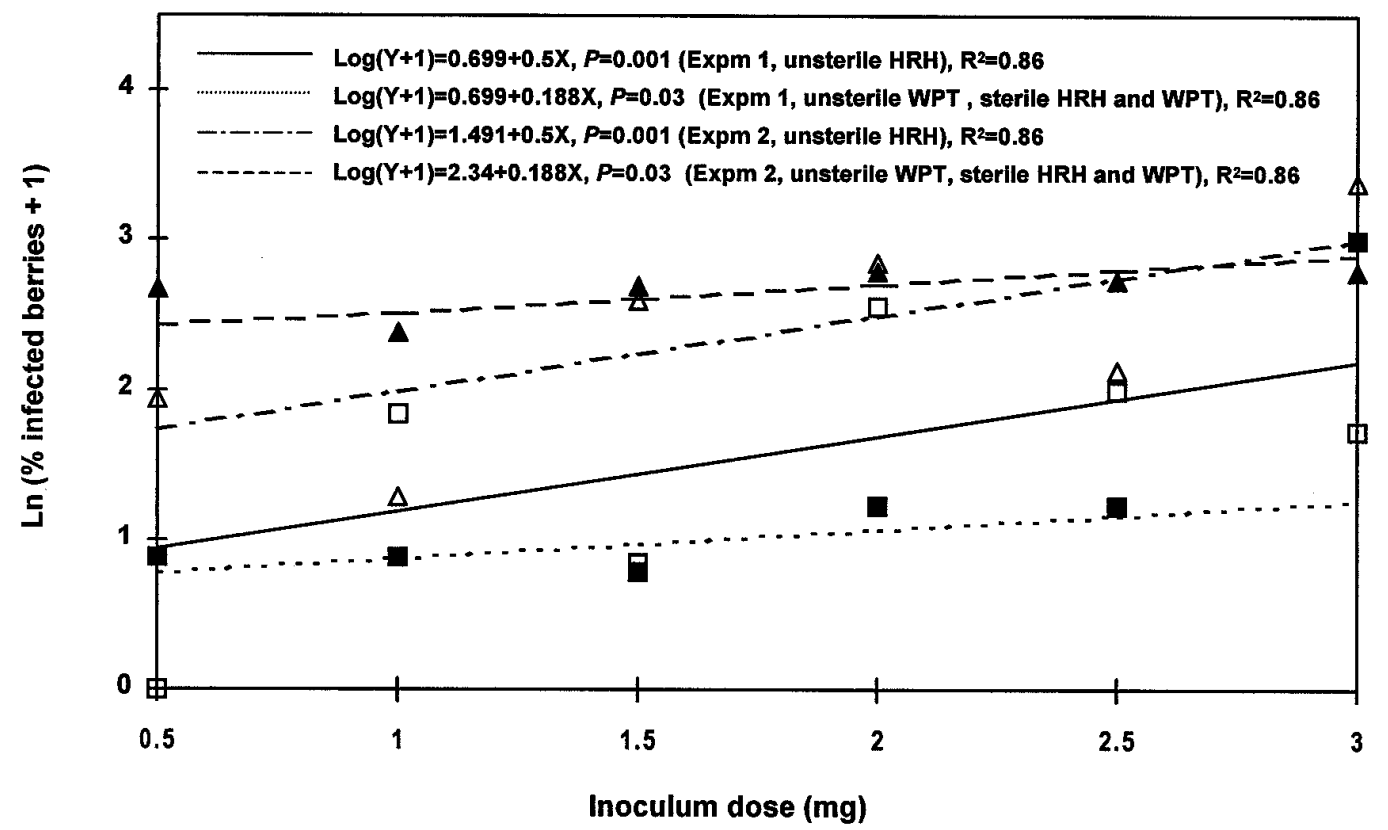

Fig. 3. Effect of wetness and sterility regime on the infectivity of single airborne conidia of Botrytis cinerea dispersed at different dosages on fresh Dauphine grape berries. Incidence of $B$. cinerea is represented by the log-transformed values of the percentage of berries yielding the pathogen 14 days after being frozen for $1 \mathrm{~h} \mathrm{at}-12^{\circ} \mathrm{C}$. Berries used in experiment 1 were inoculated on the day following harvest, whereas those in experiment 2 were inoculated after 1 week of storage at $5^{\circ} \mathrm{C}$. Data of treatments that did not differ significantly are represented by the same line. Points represent actual means. $R^{2}$ for full regression model was 0.86 . 
opment of established infections (22). Contrary to the cold-stored berries, lesions developed on fresh berries and on skin segments predominantly from one site. A minority of the fresh berries therefore allowed a few of the single conidia to penetrate the cuticle.

These findings indicated that the resistance to infection conferred by the cuticle and the few underlying cells of ripe Dauphine grape berries was negated by $\mathrm{SO}_{2}$ treatment and prolonged cold storage. Grapes are normally considered relatively susceptible to decay by groups of conidia when mature $(2,19,34,41)$, and the pathogen readily causes decay on mature Dauphine table grape berries inoculated with conidial suspensions (22).

In most studies where grapes were artificially inoculated, berries were atomized with $(8,33,36,41)$, dipped in $(2)$, or injected with $(1,30,56)$ conidial suspensions, or suspension droplets were placed onto the berry cheek $(5,29)$. These methods allowed for the deposition of groups of conidia and may differ from primary natural inoculation in the vineyard, where single conidia may be deposited simultaneously at several sites on the berry surface. Deposition of groups of conidia at a single site could alter the host response to infection and hence the estimate of susceptibility. In the vineyard, the frequent runoff of raindrops would promote faster drying of berries and a lower incidence of infection than might be expected from laboratory-inoculated berries. In the latter instance, droplets deposited on berries remained undisturbed for longer periods, which could enhance germ tube and hyphal growth, thereby

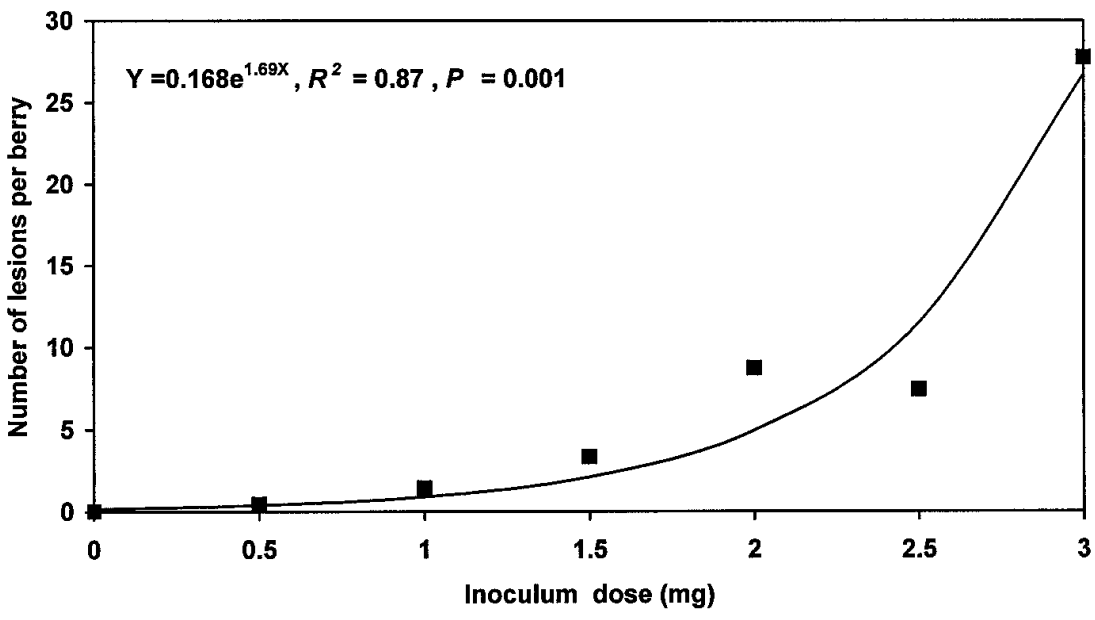

Fig. 5. Mean number of lesions formed on cold-stored Dauphine grape berries 3 days after inoculation with different dosages of single airborne conidia of Botrytis cinerea and $24 \mathrm{~h}$ of incubation at high relative humidity $(\geq 93 \%)$. Berries were obtained from bunches harvested at vintage and subjected to $\mathrm{SO}_{2}$ treatment and 8 weeks of storage at $-0.5^{\circ} \mathrm{C}$. Points represent actual means from two experiments.

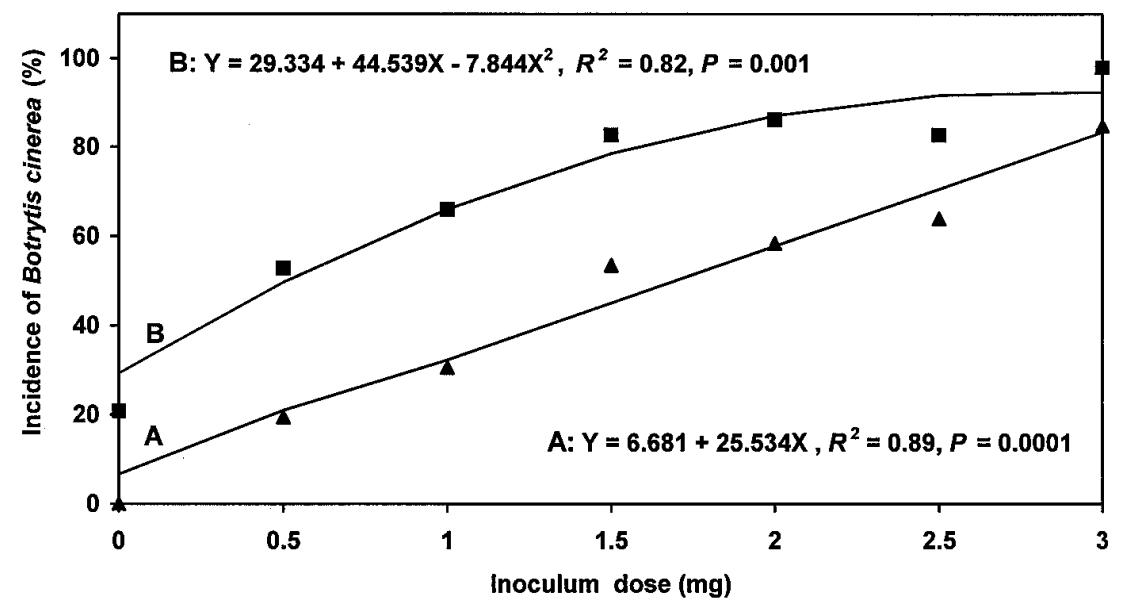

Fig. 6. Mean percentage of cold-stored Dauphine grape berries showing lesions 3 days, or yielding the pathogen 14 days, after inoculation with different dosages of single airborne conidia of Botrytis cinerea and $24 \mathrm{~h}$ of incubation at high relative humidity $(\geq 93 \%)$. Berries were obtained from bunches harvested at vintage and subjected to $\mathrm{SO}_{2}$ treatment and 8 weeks of storage at $-0.5^{\circ} \mathrm{C}$. Berries were rated 3 days after inoculation (A), frozen, and rated again after 14 days (B). Points represent actual means from two experiments. facilitating its chance of contacting suitable sites for penetration, such as stomata and microcracks $(6,59)$. This study showed that inoculation with single airborne conidia rather than groups of conidia per site is highly desirable, especially in quantitative studies such as those on host responses, where a better uniformity in conidial deposition is needed, or those on biological control, where the interaction between the pathogen and an antagonists is evaluated.

Different infection pathways have been described for conidial infection by $B$. cinerea on grape berries, namely style ends $(31,40)$, pedicels $(20,21,46)$, natural openings (47), wounds (36), or by direct penetration of the cuticle (42). Of these, wounding has been regarded as a major entry site $(12,19,36)$. However, there are reports (41) that indicate that wounded grapes are no more susceptible to the pathogen than unwounded grapes. Nelson (42) inoculated mature Tokay grapes that had been in cold storage for 10 weeks at $0^{\circ} \mathrm{C}$ and found evidence of direct penetration through the intact cuticle. However, Nelson (41) expressed the view that the combination of cold storage and $\mathrm{SO}_{2}$ treatment reduces the natural resistance of mature grape berries to infection and facilitates direct penetration. The low incidence of disease caused by single conidia on fresh berries, and high incidence of disease on berries subjected to $\mathrm{SO}_{2}$ treatment and prolonged cold storage, substantiates this view. Since relatively high infection rates often occur in vineyards (38), these findings suggest that the role of predisposing factors such as wounding may be underestimated in the epidemiology of $B$. cinerea. Grape berries can be wounded by insects, frost, hail, windblown sand, sun, or rapid water intake leading to splitting $(25,51)$. Insects can play a very prominent role in this event. Fermaud and Le Menn (15) showed that larvae of Lobesia botrana carried viable conidia of $B$. cinerea externally or internally. According to Fermaud and Le Menn (16), the introduction of conidia into wounds by L. botrana is important in the initiation of rot during the stages before véraison.

Infection studies with conidial suspensions of $B$. cinerea on different hosts proved that increasing concentrations of conidia led to higher infections and lesion formation $(13,52,57,58)$. Working with single airborne conidia of the pathogen on ripe Dauphine table grapes, we found that the disease reaction is not governed by conidial density on berry surfaces, but by the level of host resistance. If infection by single airborne conidia is of importance in primary infection events in vineyards, this finding can have a major impact on the validation of disease prediction models for grapevine. These models are primarily based on the behavior of groups of conidia after inoculation with conidial suspensions on mature berries. Based on that data, $B$. 
cinerea bunch rot epidemics on grapes are described as weather driven $(2,55)$, inoculum driven (37), or depending on climatic conditions, determined by inoculum or weather conditions (35). We argue that the inoculation method used enables us to partially reproduce natural dispersal of, and infection by, single airborne conidia, and that the disease reaction induced by single airborne conidia on berries of different ripeness can supply more information on the infectivity of natural inoculum applied during the resistant (setting to véraison) and susceptible (véraison to harvest) stages of grapevine. More information is therefore needed on the behavior of the different types of $B$. cinerea inocula (single airborne conidia, groups of conidia, mycelia) at the different phenological stages of grapevine to validate disease prediction models.

\section{ACKNOWLEDGMENTS}

This work was partially supported by grants from Unifruco Research Services. We thank A. Sadie (ARC-Agrimetry Institute, Private Bag X5013, Stellenbosch 7599) and K. Pringle (Department of Entomology and Nematology, University of Stellenbosch, Private Bag X1, Matieland 7602) for helping with the statistical analyses and E. J. Havinga for technical assistance.

\section{LITERATURE CITED}

1. Avissar, I., and Pesis, E. 1991. The control of postharvest decay in table grapes using acetaldehyde vapours. Ann. Appl. Biol. 118:229237.

2. Broome, J. C., English, J. T., Marois, J. J., Latorre, B. A., and Aviles, J. C. 1995. Development of an infection model for Botrytis bunch rot of grapes based on wetness duration and temperature. Phytopathology 85:97-102.

3. Bulit, J., and Lafon, R. 1970. Quelques aspects de la biologie du Botrytis cinerea Pers., agent de la pourriture grise des raisins. Vigne Vin 4:159-174.

4. Bulit, J., and Verdu, D. 1973. Annual variations in the aerial sporing of Botrytis cinerea in a vineyard. Proc. Eur. Botrytis Symp., 28 June -1 July, Teresin, Poland.

5. Chardonnet, C., L'Hyvernay, A., and Doneche, B. 1997. Effect of calcium treatment prior to Botrytis cinerea infection on the changes in pectic composition of grape berry. Physiol. Mol. Plant Pathol. 50:213-218.

6. Clark, C. A., and Lorbeer, J. W. 1976. Comparative histopathology of Botrytis squamosa and $B$. cinerea on onion leaves. Phytopathology 66:1279-1289.

7. Corbaz, R. 1972. Etudes des spores fongiques captées dans l'air. Phytopathol. Z. 74:318328.

8. De Kock, P. J., and Holz, G. 1991. Colonization of table grapes by Botrytis cinerea in the Western Cape province. Phytophylactica 23:73-80.

9. Doss, R. P., Potter, S. W., Chastagner, G. A, and Christain, J. K. 1993. Adhesion of nongerminated Botrytis cinerea conidia to several substrata. Appl. Environ. Microbiol. 59:1786-1791.

10. Doss, R. P., Potter, S. W., Soeldner, A. H., Christain, J. K., and Fukunaga, L. E. 1995. Adhesion of germlings of Botrytis cinerea. Appl. Environ. Microbiol. 61:206-265.

11. Duncan, R. A., Stapleton, J. J., and Leavitt, G. M. 1995. Population dynamics of epiphytic mycoflora and occurrence of bunch rots of wine grapes as influenced by leaf removal.
Plant Pathol. 44:956-965.

12. Du Plessis, S. J. 1937. Botrytis rot of grapes, and its control during 1933-1934. Farming SA 9:395-397, 439-442.

13. Eden, M. A., Hill, R. A., Beresford, R., and Stewart, A. 1996. The influence of inoculum concentration, relative humidity, and temperature on infection of greenhouse tomatoes by Botrytis cinerea. Plant Pathol. 45:798-806.

14. Fermaud, M., and Gaunt, R. 1995. Thrips obscuratus as a potential vector of Botrytis cinerea in kiwifruit. Mycol. Res. 99:267-273.

15. Fermaud, M., and Le Menn, R. 1989. Association of Botrytis cinerea with grape berry moth larvae. Phytopathology 79:651-656.

16. Fermaud, M., and Le Menn, R. 1992. Transmission of Botrytis cinerea to grapes by grape berry moth larvae. Phytopathology 82:13931398.

17. Gessler, A., and Jermini, M. 1985. Role of flower infections of grape by Botrytis cinerea and consequences for the spraying schedule. Quad. Vitic. Enol., Univ. Torino 9:245-250.

18. Hill, G. 1985. Suberization of cell walls: A defence reaction of grape stem tissue against invading mycelium of Botrytis cinerea. Quad. Vitic. Enol., Univ. Torino 9:229-230.

19. Hill, G., Stellwaag-Kittler, F., Huth, G., and Schlösser, E. 1981. Resistance of grapes in different developmental stages to Botrytis cinerea. Phytopathol. Z. 102:328-338.

20. Holz, G., Coertze, S., and Basson, E. J. 1997. Latent infection of Botrytis cinerea in grape pedicels leads to postharvest decay. Phytopathology 87:S43.

21. Holz, G., Coertze, S., and Basson, E. J. 1998. Infection pathways and latency of Botrytis cinerea in grape bunches. (Abstr.) Int. Congr. of Plant Pathol., 7th, Edinburgh, Scotland. Vol. 3:6.22.

22. Holz, G., Körte, V., and Coertze, S. 1995. Behaviour of Botrytis cinerea on grape, nectarine and plum fruit surfaces under different wetness regimes. Page 56 in: Scientific Programme and Abstracts. Bien. Aust. Plant Pathol. Soc. Conf., 10th. Lincoln University, New Zealand.

23. Jarvis, W. R. 1962. The dispersal of spores of Botrytis cinerea Fr. in a raspberry plantation. Trans. Br. Mycol. Soc. 45:549-559.

24. Jarvis, W. R. 1962. Splash dispersal of spores of Botrytis cinerea Pers. Nature (London) 193:599.

25. Jarvis, W. R. 1980. Epidemiology. Pages 219250 in: The biology of Botrytis. J. R ColeySmith, K. Verhoeff, and W. R. Jarvis, eds. Academic Press, New York.

26. Kerssies, A. 1990. A selective medium for Botrytis cinerea to be used in a spore-trap. Neth. J. Plant Pathol. 96:247-250.

27. Laszlo, J. C., Combrink, J. C., Eksteen, G. J., and Truter, A. B. 1981. Effect of temperature on the emission of sulphur dioxide from gas generators for grapes. Decid. Fruit Grow. 31:112-119.

28. Louis, C., Girard, M., Kuhl, G., and LopezFerber, M. 1996. Persistence of Botrytis cinerea in its vector Drosophila melanogaster. Phytopathology 86:934-939.

29. Marois, J. J., Bledsoe, A. M., Bostock, R. M., and Gubler, W. D. 1987. Effects of spray adjuvants on development of Botrytis cinerea on Vitis vinifera berries. Phytopathology 77:1148-1152.

30. Marois, J. J., Bledsoe, A. M., Gubler, W. D., and Luvisi, D. A. 1986. Control of Botrytis cinerea on grape berries during postharvest storage with reduced levels of sulfur dioxide. Plant Dis. 70:1050-1052.

31. McClellan, W. D., and Hewitt, B. 1973. Early Botrytis rot of grapes: Time of infection and latency of Botrytis cinerea Pers. in Vitis vinifera L. Phytopathology 63:1151-1157.
32. Molot, B. 1987. La Modélisation de la pourriture grise de la vigne par systéme d'E.P.I. Prog. Agric. Vitic. 104:355-358.

33. Nair, N. G. 1985. Fungi associated with bunch rot of grapes in the Hunter Valley. Aust. J. Agric. Res. 36:435-442.

34. Nair, N. G., and Allen, R. N. 1993. Infection of grape flowers and berries by Botrytis cinerea as a function of time and temperature. Mycol. Res. 97:1012-1014.

35. Nair, N. G., and Balasubramaniam, R. 1995. Operational research on Botrytis bunch rot disease management in Australian and New Zealand viticulture. Aust. N.Z. Wine Indust. J. 10:237-240.

36. Nair, N. G., Emmett, R. W., and Parker, F. E. 1988. Some factors predisposing grape berries to infection by Botrytis cinerea. N.Z. J. Exp. Agric. 16:257-263.

37. Nair, N. G., Guilbaud-Oulton, S., Barchia, I., and Emmett, R. 1995. Significance of carry over inoculum, flower infection and latency on the incidence of Botrytis cinerea in berries of grapevines at harvest in New South Wales. Aust. J. Exp. Agric. 35:1177-1180.

38. Nair, N. G., and Hill, G. K. 1992. Bunch rot of grapes caused by Botrytis cinerea. Pages 147-169 in: Plant Diseases of International Importance. Vol III: Diseases of Fruit Crops. J. Kumar, H. S. Chaube, U. S. Singh, and A. N. Mukhopadhyoy, eds. Prentice Hall, Englewood Cliffs, NJ.

39. Nair, N. G., and Nadtotchei, A. 1987. Sclerotia of Botrytis as a source of primary inoculum for bunch rot of grapes in New South Wales, Australia. J. Phytopathol. 119:42-51.

40. Nair, N. G., and Parker, F. E. 1985. Midseason bunch rot of grapes: An unusual disease phenomenon in the Hunter Valley, Australia. Plant Pathol. 34:302-305

41. Nelson, K. E. 1951. Effect of humidity on infection of table grapes by Botrytis cinerea. Phytopathology 41:859-864.

42. Nelson, K. E. 1956. The effect of Botrytis infection on the tissue of Tokay grapes. Phytopathology 46:223-229.

43. Nelson, K. E. 1983. Effects of in-package sulfur dioxide generators, package liners, and temperature on decay and desiccation of table grapes. Am. J. Enol. Vitic. 34:10-16.

44. Northover, J. 1987. Infection sites and fungicidal prevention of Botrytis cinerea bunch rot of grapes in Ontario. Can. J. Plant Pathol. 9:129-136.

45. O'Brien, T. P., and McCully, M. E. 1981. The study of Plant Structure Principles and Selected Methods. Termarcarphi Pty. Ltd., Melbourne, Australia.

46. Pezet, R., and Pont, V. 1986. Infection florale et latence de Botrytis cinerea dans les grappes de Vitis vinifera (var. Gamay). Revue suisse Vitic. Arboric. Hortic. 18:317-322.

47. Pucheu-Planté, B., and Mercier, M. 1983. Étude ultrastructurale de l'interrelation hôteparasite entre le raisin et le champignon $\mathrm{Bo}$ trytis cinerea: Exemple de la pourriture noble en Sauternais. Can. J. Bot. 61:1785-1797.

48. Salinas, J., Glandorf, D. C. M., Picavet, F. D., and Verhoeff, K. 1989. Effects of temperature, relative humidity and age of conidia in the incidence of spotting on gerbera flowers caused by Botrytis cinerea. Neth. J. Plant Pathol. 95:51-64.

49. Sarig, P., Zahavi, T., Zutkhi, Y., Yannai, S., Lisker, N., and Ben-Arie, R. 1996. Ozone for control of post-harvest decay of table grapes caused by Rhizopus stolonifer. Physiol. Mol. Plant Pathol. 48:403-415.

50. Sarig, P., Zutkhi, Y., Monjauze, A., Lisker, N. and Ben-Arie, R. 1997. Phytoalexin elicitation in grape berries and their susceptibility to Rhizopus stolonifer. Physiol. Mol. Plant $\mathrm{Pa}-$ thol. 50:337-347. 
51. Savage, S. D., and Sall, M. A. 1983. Botrytis bunch rot of grapes: The influence of selected cultural practices on infection under California conditions. Plant Dis. 67:771-774.

52. Sirjusingh, C., Sutton, J. C., and Tsujita, M. J. 1996. Effects of inoculum concentration and host age on infection of geranium by Botrytis cinerea. Plant Dis. 80:154-159.

53. Snedecor, G. W., and Cochran, W. G. 1980. Statistical Methods. 7th ed. Iowa State University, Ames.

54. Spotts, R. A., and Holz, G. 1996. Adhesion and removal of conidia of Botrytis cinerea and Penicillium expansum from grape and plum fruit surfaces. Plant Dis. 80:688-691.

55. Strizyk, S. 1983. Modele d'etat potentiel d'infection application au Botrytis cinerea. Version 1983. Association de coordination technique agricole, France.

56. Thomas, C. S., Marois, J. J., and English, J. T. 1988. The effects of wind speed, temperature, and relative humidity on development of aerial mycelium and conidia of Botrytis cinerea on grape. Phytopathology 78:260-265.

57. Van den Heuvel, J. 1981. Effect of inoculum composition on infection of French bean leaves by conidia of Botrytis cinerea. Neth. J. Plant Pathol. 87:55-64.

58. Van den Heuvel, J., and Waterreus, L. P. 1983. Conidial concentration as an important factor determining the type of prepenetration structures formed by Botrytis cinerea on leaves of French bean (Phaseolus vulgaris). Plant $\mathrm{Pa}$ thol. 32:263-272.

59. Wildman, H. G., and Parkinson, D. 1981 Comparison of germination of Cladosporium herbarum and Botrytis cinerea conidia in vitro in relation to nutrient conditions on leaf surfaces. Can. J. Bot. 59:854-861. 